कू

A Comparison of Least Squares Linear Regression and Measurement Error Modeling of Warm/Cold Multipole Correlation in SSC Prototype Dipole Magnets

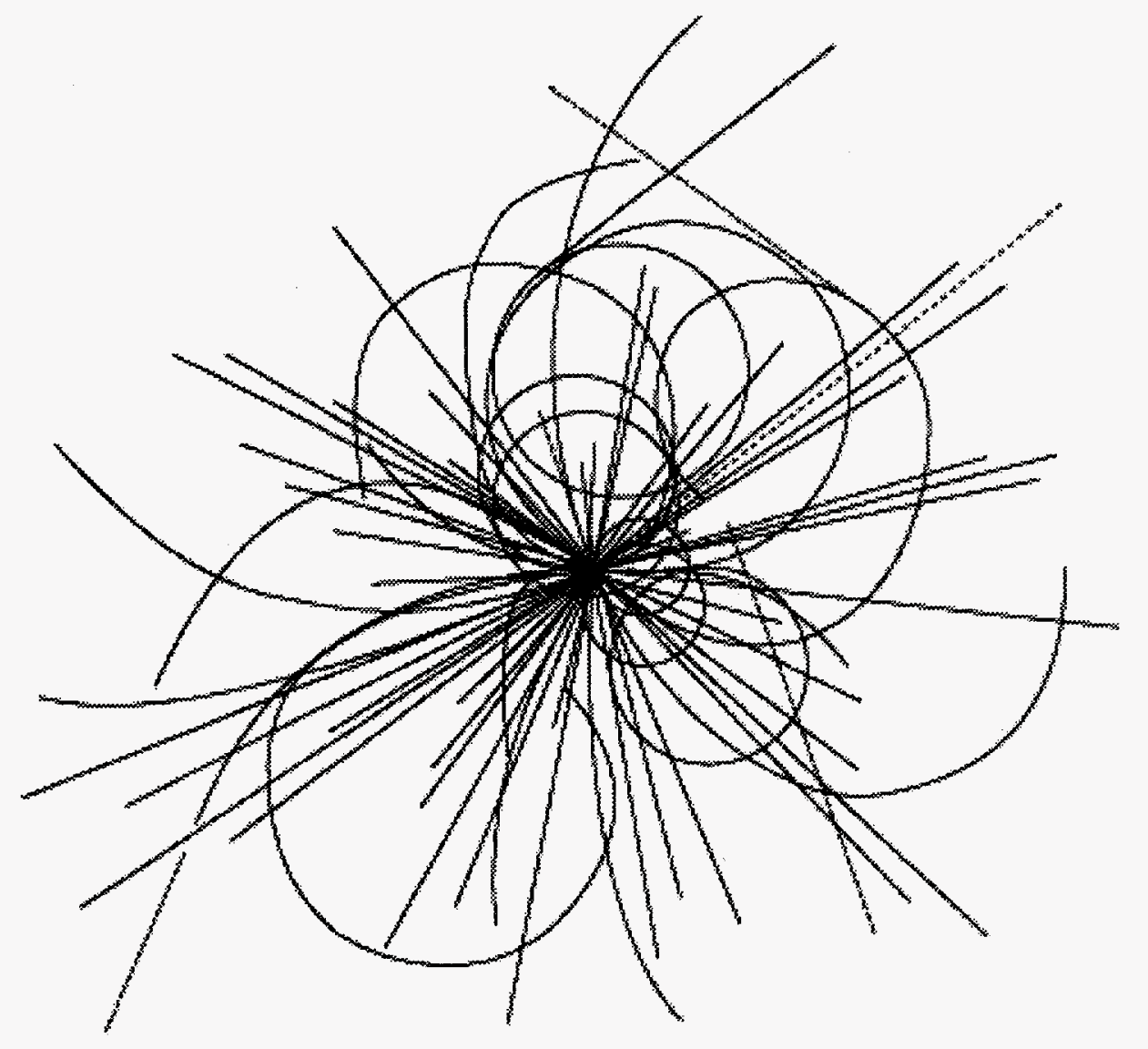

Superconducting Super Collider Laboratory

D. Pollock

R. Gunst

K. Kim

W. Schucany

APPROVED FOR RELEASE OR

PUBLICATION - O.R. PATENT GROUP BY... 6 ....... DATE. $413 / 9.5$. 
Disclaimer Notice

This report was prepared as an account of work sponsored by an agency of the United States Govemment. Nelther the United States Government or any agency thereot, nor any of their employees, makes any warranty, express or implied, or assumes any legal liability or responsibility for the accuracy, completeness, or usefulness of any information, apparatus, product, or process disclosed, or represents that its use would not intringe privately owned rights. Reference herein to any specific commercial product, process, or service by trade name, trademark, manufacturer, or otherwise, does not necessarily constitute or imply its endorsement, recommendation, or favoring by the United States Government or any agency thereot. The views and opinions of authors expressed herein do not necessarily state or reflect those of the United States Govemment or any agency thereot.

Superconducting Super Collider Laboratory is an equal opportunity employer. 


\section{DISCLAIMER}

Portions of this document may be illegible in electronic image products. Images are produced from the best available original document. 


\title{
A Comparison of Least Squares Linear Regression and Measurement Error Modeling of Warm/Cold Multipole Correlation in SSC Prototype Dipole Magnets ${ }^{*}$
}

\author{
D. Pollock and K. Kim \\ Superconducting Super Collider Laboratory ${ }^{\dagger}$ \\ 2550 Beckleymeade Ave. \\ Dallas, TX 75237 \\ R. Gunst and W. Schucany \\ Southern Methodist University \\ Dallas, TX 75275
}

May 1993

"Presented at the Fifth Annual International Symposium on the Super Collider, May 6-8, 1993 San Francisco, CA. tOperated by the Universities Research Association, Inc., for the U.S. Department of Energy under Contract No. DE-AC35-89ER40486. 


\title{
A COMPARISON OF LEAST SQUARES LINEAR REGRESSION AND MEASUREMENT ERROR MODELING OF WARM / COLD MULTIPOLE CORRELATION IN SSC PROTOTYPE DIPOLE MAGNETS
}

\author{
D. A. Pollock, ${ }^{1}$ R. F. Gunst, ${ }^{2}$ K. Kim, ${ }^{1}$ and W. R. Schucany ${ }^{2}$ \\ ${ }^{1}$ Superconducting Super Collider Laboratory, Dallas, Texas $75237^{*}$ \\ ${ }^{2}$ Southern Methodist University, Dallas, Texas 75275
}

\section{INTRODUCTION}

Linear estimation of cold magnetic field quality based on warm multipole measurements is being considered as a quality control method for SSC production magnet acceptance. To investigate prediction uncertainties associated with such an approach, axial-scan (Z-scan) magnetic measurements from SSC Prototype Collider Dipole Magnets (CDM's) have been studied. This paper presents a preliminary evaluation of the explanatory ability of warm measurement multipole variation on the prediction of cold magnet multipoles. Two linear estimation methods are presented: least-squares regression, which uses the assumption of fixed independent variable $\left(x_{i}\right)$ observations, and the measurement error model, which includes measurement error in the $x_{i}{ }^{\prime} s$. The influence of warm multipole measurement errors on predicted cold magnet multipole averages is considered.

MSD QA is studying warm/cold correlation to answer several magnet quality control questions. How well do warm measurements predict cold (2kA) multipoles? Does sampling error significantly influence estimates of the linear coefficients (slope, intercept and residual standard error)? Is estimation error for the predicted cold magnet average small compared to typical variation along the Z-Axis? What fraction of the multipole RMS tolerance is accounted for by individual magnet prediction uncertainty?

\section{THE DATA}

To compare the two linear estimation models, the joint behavior of warm/cold multipole pairs have been studied. The data selected is from six CDM's (DCA311, 312, $314,315,317$, and 319) which were measured at FNAL using mole B2. The data includes multipoles $\left(a_{n}\right.$ and $\left.b_{n}, n=1,11\right)$ which were measured at $24 \mathrm{Z}$-scan positions (between -7.01 and $7.01 \mathrm{~m})$ for each magnet under both cold $(2 \mathrm{kA})$ and warm $(+/-10 \mathrm{~A})$ conditions. The reported values are the position average of repetitive coil rotations. Also, the measurements have been centering corrected. Traditional linear regression assumptions regarding independence, constant variance and normality have been verified for the source data using graphical residual analysis techniques. ${ }^{1}$ Research results for the $b_{2}$ (normal sextupole) multipole will be demonstrated in this paper.

*Operated by the Universities Research Association, Inc., for the U.S. Department of Energy under Contract No. DE-AC35-89ER40486. 


\section{COMPARING ORDINARY LEAST SQUARES AND MEASUREMENT ERROR MODEL FITS}

Ordinary Least Squares (OLS) is typically used to estimate the relationship between paired observations for which $y$ is assumed to be linearly dependent on or explained by $x$. For the Warm/Cold multipole study, $y_{i}$ is a cold multipole observation (mole-position average), $x_{i}$ is a warm multipole observation. The dependent variable is traditionally assumed to be "fixed", (i.e., observed without error).

Since the Warm observations are not fixed (i.e., each individual coil rotation at a given mole-position generates a different result), the OLS prediction model is subject to both random and measurement errors. According to linear estimation theory, the predicted slope, intercept and residual standard error using the OLS model under such conditions will be biased.2.3 Without adjusting for the measurement error, the cold prediction model will underestimate the slope. In the case that $x$ and $y$ are themselves random variables (i.e., error-free cold and warm multipole measurements are each random variables based on samples from several coil-rotations) the traditional linear model assumptions should be replaced by a Measurement Error Model. ${ }^{3}$

The key to applying the measurement error model (MEM) to cold multipole predictions is determining the value of the ratio of error variances $(\lambda)$ which for our example is defined as the ratio of (variance cold) / (variance warm). To estimate $\lambda$, sample variance for both warm and cold multipoles by position (using individual coil rotations) within individual magnets have been calculated. The position variance estimate has been calculated as the average of individual position variances for all Z-scan positions and available magnets. Outliers were removed by using the Shewhart Variance Control Chart. Extreme values due to magnet end effects and strain gauge packs were also removed. The estimated $\lambda$ for the $b_{2}$ data is 0.000392 units. It should be noted that a recent upgrade to the SSCL magnetic measuring system has reduced warm position variance significantly. ${ }^{4}$ The data in this study are for measurements taken before the improvement was introduced.

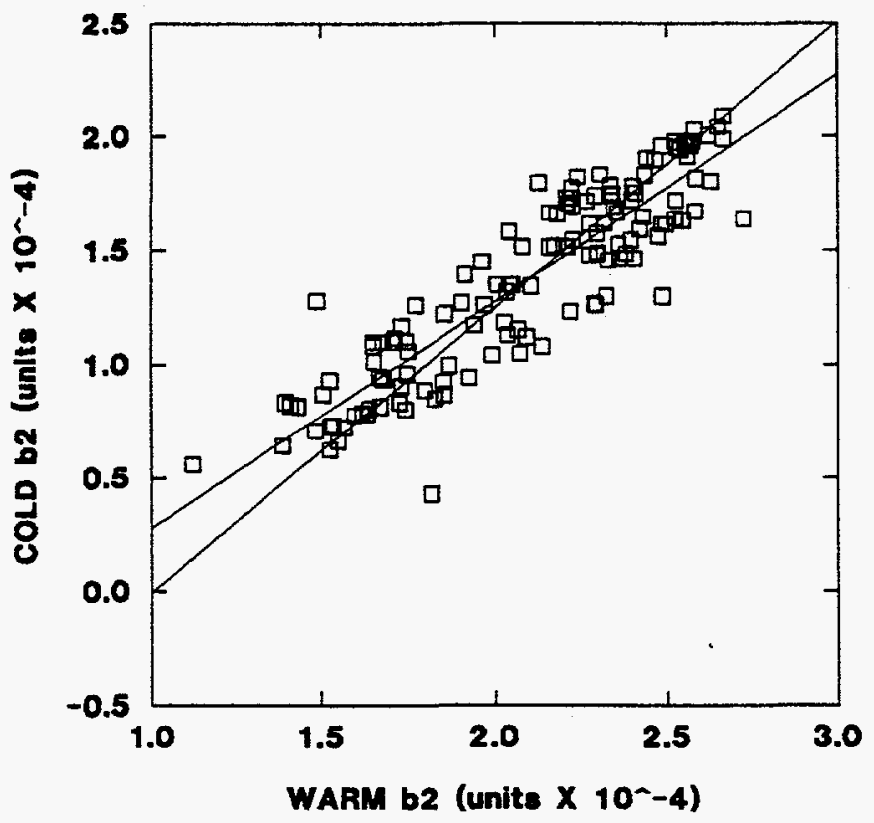

Figure 1. Warm vs. Cold $b_{2}$. The linear fits using OLS (shallower slope) and MEM (steeper slope) methods. Data does not include strain gauge position values.

A comparison of OLS and MEM prediction equations for $b_{2}$ is shown in Figure 1 . The figure shows how the OLS estimate tends to under-estimate the slope. The estimated coefficients (slope, intercept and residual standard error) and a 95\% prediction interval for both OLS and MEM models of individual mole-position estimates are listed in Table 1. The wider $95 \%$ prediction interval for the MEM estimate shown in Table 1 is due to including measurement error $(\lambda)$. 
Table 1. Comparing OLS and MEM Estimates of Cold $b_{2}$ by Mole-Position

\begin{tabular}{|c|c|c|c|c|}
\hline Estimate & Slope & Intercept & $\begin{array}{l}\text { Std. Error } \\
\text { of Residuals }\end{array}$ & $\begin{array}{l}\text { 95\% Prediction Interval *** } \\
\text { (1 sided, at mean warm value) }\end{array}$ \\
\hline $\begin{array}{l}\text { OLS * } \\
\text { OLS ** } \\
\text { MEM * } \\
\text { MEM ** }\end{array}$ & $\begin{array}{l}0.976 \\
0.997 \\
1.397 \\
1.256\end{array}$ & $\begin{array}{l}-0.717 \\
-0.718 \\
-1.600 \\
-1.263\end{array}$ & $\begin{array}{l}0.23319 \\
0.18397 \\
0.27892 \\
0.20762\end{array}$ & $\begin{array}{l}0.46023 \\
0.36194 \\
0.54875 \\
0.40847\end{array}$ \\
\hline
\end{tabular}

Both the OLS and MEM prediction methods have been used to estimate cold multipoles by Z-position. See Figure 2 "Warm/Cold $b_{2}$ Estimates by Mole-Position (DCA311)" for an example of the predictions by position. Based on One Way Analysis of Variance (ANOVA) of DCA311 warm multipole coil-rotation data, the average variance "within" position (i.e., due to measurement error) is 0.01482 units and the "between" postion variance is 0.12842 units. Differences due to position (i.e. manufacturing variation along the length of the magnet) explain approximately $92 \%$ of the variance in DCA311 warm $b_{2}$. Similarly, differences due to position explain approximately $99 \%$ of the variance in DCA 311 cold $b_{2}$. In both cases, measurement error is very small compared to variation along the magnet.

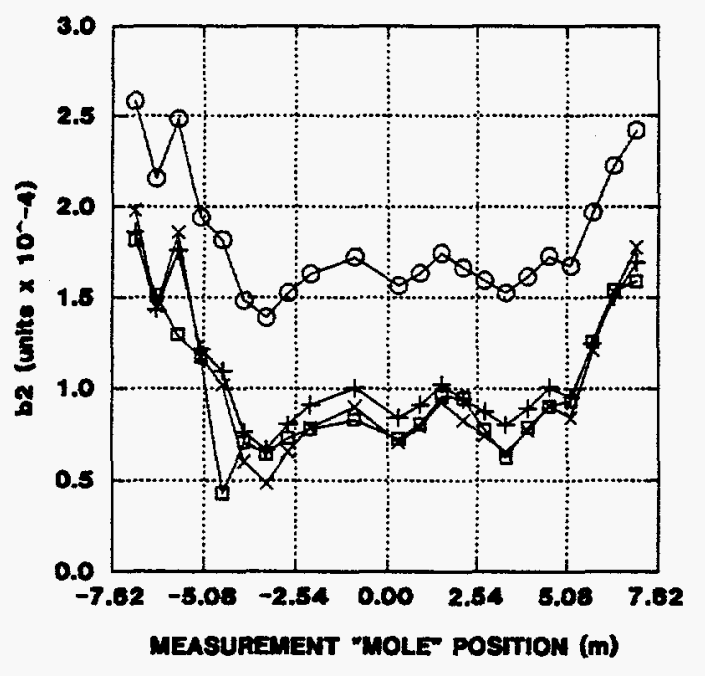

$\times$ MEM EST. (no $8 / 0)$

+ OLS EST. (no $s / C)$

- Cold be (pos ave)

O wanim b2 (pos avo)

Figure 2. Warm/Cold $b_{2}$ Estimate by Mole-Position (DCA311). Strain gauge effets are not shown. Predicted cold multipole values by mole-position are plotted using OLS and MEM methods. Actual Warm and Cold Measurements are shown for comparison.

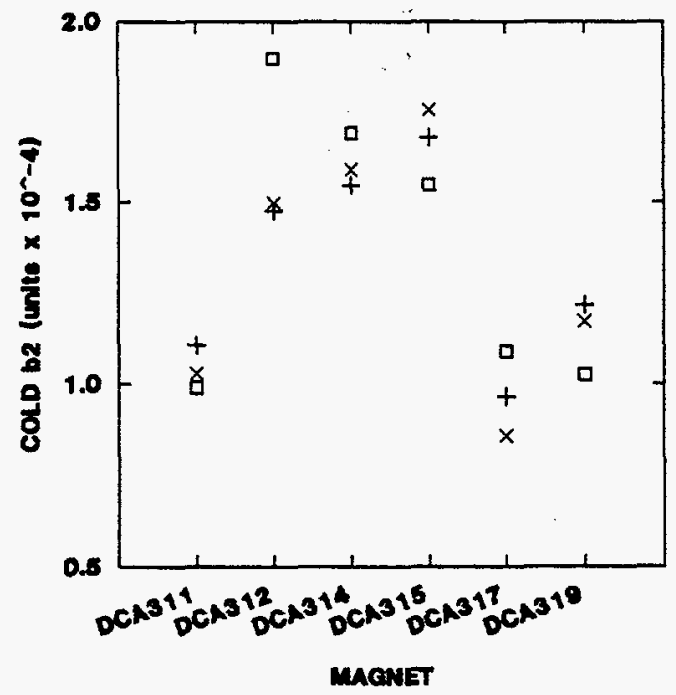

\footnotetext{
$\times$ MEN EST. (no $\mathrm{s} / \mathrm{Q})$

+ OLs EsT. (no $s / C$ )

a colo be maenet ave
}

Figure 3. Warm/Cold b2 Estimate of Magnet Averages. Mole-position values have been averaged over the length of the magnet, without positions -0.31 , and -1.52 (strain gauge effects).

\section{PREDICTING COLD MAGNET AVERAGE MULTIPOLE VALUES}

For magnet acceptance purposes, the magnet mean of the multipoles is of primary interest. The magnet mean is estimated as an average of the position measurements (or predictions). A summary of magnet mean predictions for $b_{2}$ is presented in Figure 3 and Table 2. From these summaries, one may compare the relative difference between the Cold measurements and the OLS or MEM estimates. The MEM prediction was closer than the OLS prediction to the measured cold mean in $4 / 6$ of the cases studied. 
Table 2. Magnet Mean Results for $b_{2}$ (normal sextupole).

Note: Position $<>-0.31 \mathrm{~m},-1.52 \mathrm{~m}$ (strain gauge effect removed), $\mathrm{n}=22$ positions per magnet. Bold indicates minimum prediction delta (absolute deifference from Cold Mean).

\begin{tabular}{lllllll}
\hline Magnet & DCA311 & DCA312 & DCA314 & DCA315 & DCA317 & DCA319 \\
\hline Cold Mean & 0.99052 & 1.89581 & 1.69006 & 1.54929 & 1.08904 & 1.02556 \\
OLS Mean & 1.10590 & 1.47492 & 1.54623 & 1.67855 & 0.96566 & 1.21579 \\
Delta OLS & 0.11538 & 0.42089 & 0.14383 & $\mathbf{0 . 1 2 9 2 6}$ & $\mathbf{0 . 1 2 3 3 8}$ & 0.19023 \\
MEM Mean & 1.02881 & 1.49925 & 1.58910 & 1.75583 & 0.85753 & 1.17272 \\
Delta MEM & $\mathbf{0 . 0 3 8 2 9}$ & $\mathbf{0 . 3 9 6 5 6}$ & $\mathbf{0 . 1 0 0 9 6}$ & 0.20654 & 0.23151 & $\mathbf{0 . 1 4 7 1 6}$ \\
\hline
\end{tabular}

\section{DISCUSSION OF QUALITY CONTROL QUESTIONS PRESENTED IN THE INTRODUCTION}

1. Using a linear model, how well do warm measurements predict cold ( $2 k A)$ multipoles? For the example presented, the average absolute difference between six cold magnet averages of $b_{2}$ and predicted magnet averages is: 0.18716 units (OLS), and 0.18684 units (ML), see Table 2.

2. Does warm measurement sampling error significantly influence estimates of the linear coefficients (slope, intercept and residual standard error)? Yes, at the "moleposition" level as demonstrated, see Table 1.

3. Is estimation error small compared to typical variation along the Z-Axis? Using the difference between the observed cold magnet average and the predicted magnet average, estimation error appears to be small. In this example the predicted magnet mean differed from the COLD measurement mean by 0.18716 units (OLS average absolute difference) and 0.18684 units (MEM), see Table 2. Using ANOVA of individual coilrotation data, measurement error was shown to be very small compared to variation along the magnet.

4. What fraction of the multipole tolerance ( $b_{2}$ RMS 1.15, Systematic 2.0 at injection, 0.8 at high current) is accounted for by individual magnet prediction uncertatinty? Based on the average absolute difference between cold and predicted magnet means, OLS estimation error accounts for approximately $16.3 \%$ of the $b 2$ RMS tolerance and $23.40 \%$ of the high field $b_{2}$ systematic tolerance, while MEM estimation error accounts for $16.2 \%$ of the RMS tolerance and $23.36 \%$ of the high field systematic tolerance.

\section{CONCLUSION}

This study has demonstrated two methods which may be considered for making cold magnet predictions from warm magnetic measurements. The study is based on a very small number of magnets. For the $b_{2}$ example presented the two estimation methods produced similar predictions of the cold mean. Recent improvements to the measurement system may make the issue of "measurement error" insignificant. Uncertainty of the predicted mean due to magnet axial variation will continue to be studied as more magnets and data become available.

\section{ACKNOWLEDGMENTS}

A. Devred, J. DiMarco (SSCL, Dallas, Texas). K. Kussmaul (Westinghouse Electric Corporation, Round Rock, Texas).

\section{REFERENCES}

1. D. C. Montgomery (1991). Introduction to Statistical Quality Control, Second Edition, John Wiley \& Sons, New York. pp. 465 - 468.

2. J.D. Jobson (1991). Applied Multivariate Data Analysis. Volume I: Regression and Experimental Design, Springer-Verlag, New York. pp. 121, 122.

3. M. Reilman, R. Gunst, and M. Lakshminarayana (1986). Stochastic Regression with Errors in Both Variables, Journal of Quality Technology, Vol. 18, No.3, pp. $162 \mathrm{ff}$.

4. J. DiMarco, et. al., Magnetic Measurements, DCA320-322, MSIM Report, September 22, 1992. 